\title{
Scanning Vibrating Electrode Technique as an application for measuring corrosion activity of carbon steel welded pipelines
}

\author{
A. Abdurrahim ${ }^{1}$ \& R. Akid ${ }^{2}$ \\ ${ }^{1}$ Petroleum Research Centre, Corrosion Research Unit, \\ Tripoli, Libya \\ ${ }^{2}$ Materials and Engineering Research Institute, \\ Sheffield Hallam University, Sheffield, UK
}

\begin{abstract}
The scanning vibrating electrode technique, also known as SVET, is a relatively new technique which offers the opportunity to obtain information concerning corrosion activity on a small scale. However, its utilisation to investigate the corrosion of welds has been limited. SVET experiments were carried out on specimens of different welded sections within two different electrolytes, e.g., $0.35 \% \mathrm{NaCl}$ solution alone and buffered $0.35 \% \mathrm{NaCl}$ solution with $\mathrm{CO}_{2}$ saturations. SVET was used during these investigations to evaluate preferential corrosion susceptibilities of weldments.
\end{abstract}

Keywords: SVET, localised corrosion, weldments.

\section{Introduction}

The scanning vibrating electrode technique (SVET) is an electrochemical method, which is able to resolve and quantify highly localised corrosion currents occurring at the metal-electrolyte interface [1]. It consists of a platinum microelectrode tip at the end of insulated wire thinned down to a fine point, positioned close to the surface to be scanned. A schematic of the SVET arrangement is given in Figure 1. The SVET microtip electrode is vibrated mechanically at a constant amplitude and frequency using a simple electromagnetic or piezoelectric driver $[2,3]$. The SVET has found a wide range of applications in the study of localised corrosion phenomena [4,5]. 


\section{Experimental work}

\subsection{Introduction}

Corrosion measurements were performed using welded carbon steel pipeline materials designated types Y8R27 (St-1) and Y8R24 (St-2). The preferential corrosion of the welded joints within chloride solution alone and buffered solution saturated with $\mathrm{CO}_{2}$ is the result of galvanic differences between the PP, HAZ and WM. The most active region suffers accelerated attack, with a reduction of the corrosion over more noble surfaces. Corrosion tests were conducted within different environments at ambient temperature. The $\mathrm{pH}$ for both environments was measured and found to be $6.3 \pm 0.3$ and $6.2 \pm 0.1$ within chloride solution alone and chloride solution with $\mathrm{CO}_{2}$ saturation respectively.

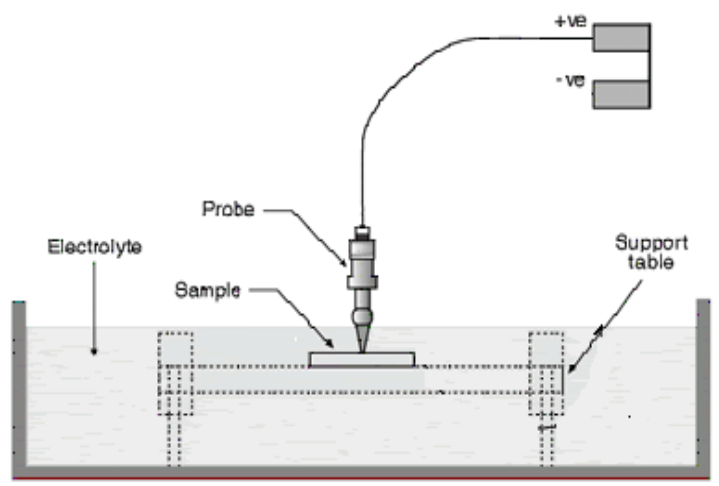

Figure 1: Schematic diagram shows SVET circuit used for measuring corrosion activity of the welded steel samples.
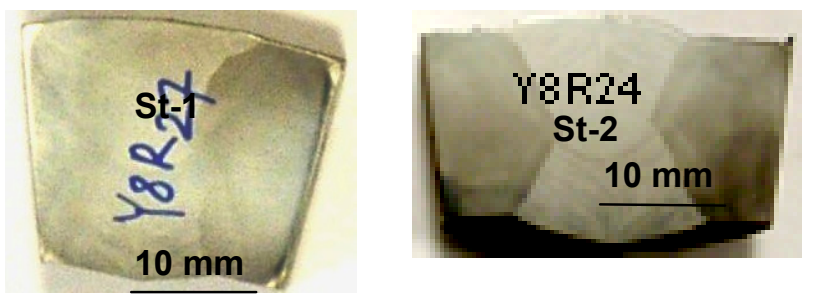

Figure 2: Schematic illustrations of the welded specimens used in the SVET tests. 


\section{Results and discussion}

\subsection{SVET measurements}

All SVET measurements were carried out within different environments using a vibrating platinum microelectrode tip, mechanically scanned at a small fixed distance from the corroding surface. SVET map scans were recorded at room temperature over a period of 1,2,3 and 4 hours.

Due to the fact that SVET resolution and output signal is dependent upon the conductivity of the solution, low conductivity solution were used for this analysis.

It should be noted that resolution and output signal decrease with increasing conductivity [6].

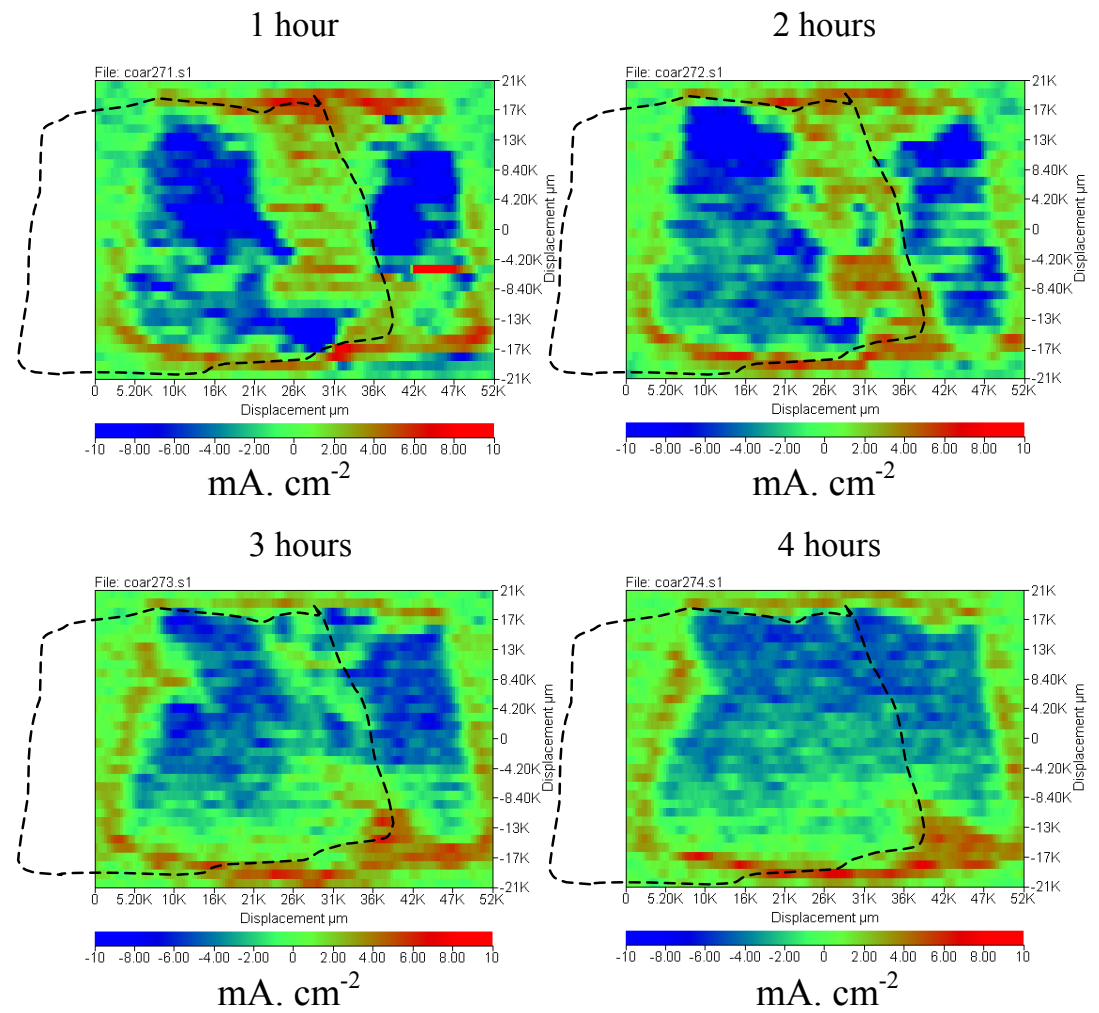

Figure 3: $\quad$ Showing the SVET area map scan on welded carbon steel pipeline designated of St-1within aqueous chloride solution for different time scans.

\subsection{SVET measurements within chloride solution}

Figures 3-4 present the area map scans of steels 1-2 respectively in sodium chloride solution. The colours at the more positive end of the palette, i.e., red, 
represents relatively cathodic potentials, whereas those at the negative end of the palette, i.e., blue, represents anodic areas. The SVET tests were conducted on the welded sections for periods of time between one and four hours due to the aggressiveness of the electrolyte, which induced highly localised attack.

The localised activity for steel-1 seemed to be concentrated on the PP and HAZ during the first two hours and being uniform over the following 3-4 hours.

Finally, the SVET maps showing the localised activity of the steel-2 was severe in the WM and HAZ whilst less activity observed in the PP during first two hours and thereafter reduced over the following 3-4 hours in the WM.
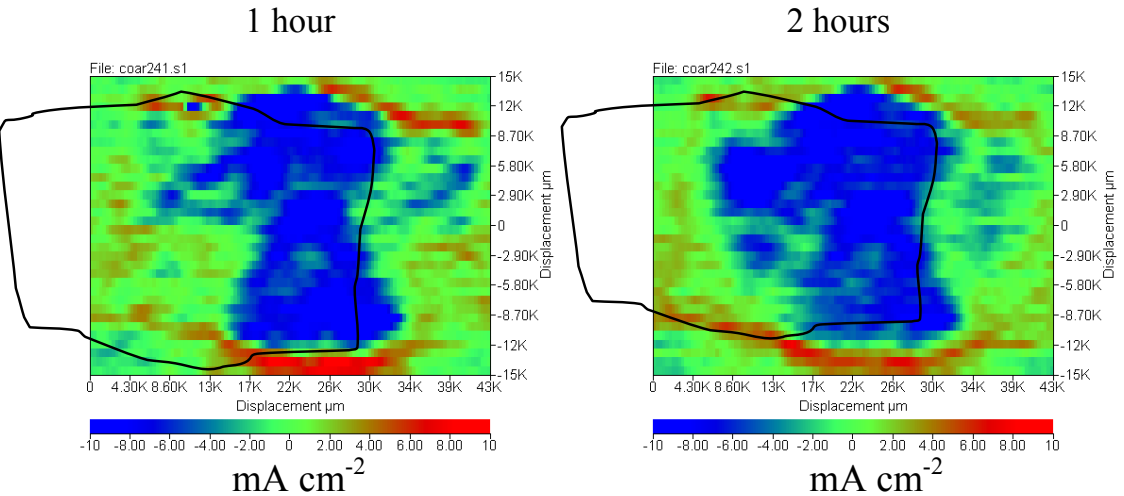

3 hours

4 hours

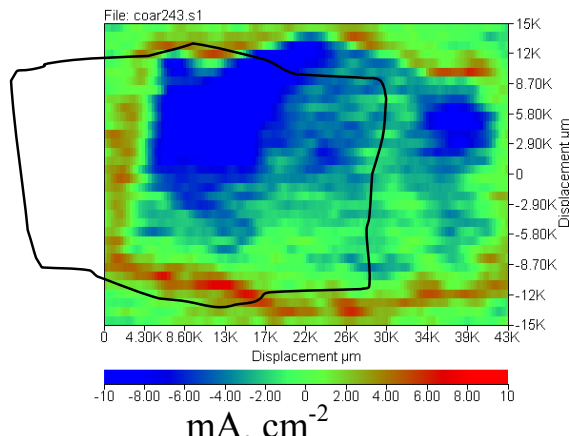

$\mathrm{mA} \cdot \mathrm{cm}^{-2}$

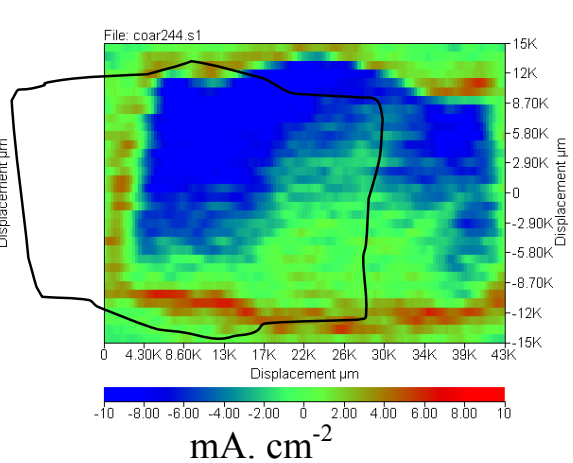

Figure 4: $\quad$ Showing the SVET area map scan on welded carbon steel pipeline designated of St-2 within chloride solution alone for different time scans.

\subsection{SVET measurements within $\mathrm{CO}_{2}$ saturations}

Figures 5-6 represent the area map scans for the different microstructures of welded steels within chloride solutions saturated with $\mathrm{CO}_{2}$. The localised attack could be seen in Figure 5, the area maps of the sites with high localised activity 
produced of the St-1 on the HAZ and to some extent at the PP and less than that on the WM during 1-2 hours and over the following 3-4 hours there is less activity on the WM and more uniform corrosion at the HAZ and PP. Figure 6 shows area map scans for steel-2, where localised activity is being uniformly during 1-4 hours for all the steel microstructures.

SVET was found to be a sensitive and reliable technique that can be used for rapid and reliable evaluation of weldments. Results of the map scans over weldments show that, although the activity varied from time to time, the most pronounced attack seemed to be concentrated in the ferrite and pearlite microstructures and least activity for some steels occurred in the bainite and martensite microstructures.

Results from the corrosion tests showed a clear significant difference in the corrosion behaviours between the weld zone and parent plate microstructures, i.e., some location for welded steel microstructures are more harmed or attacked than others.

1 hour

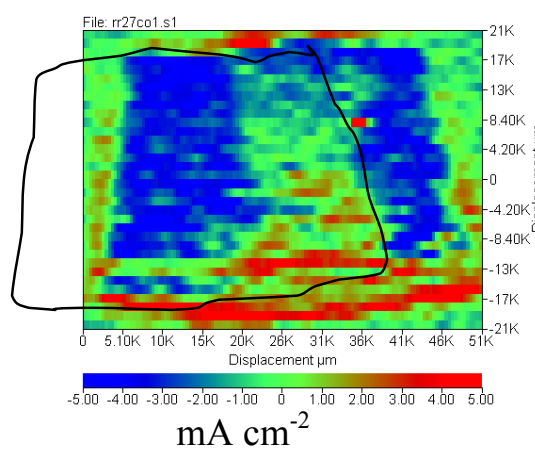

3 hours

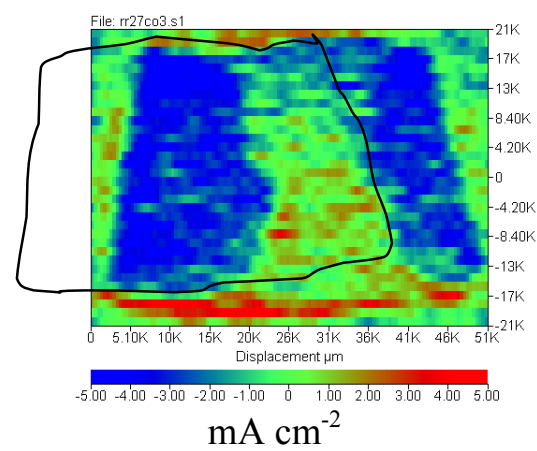

\section{2 hours}

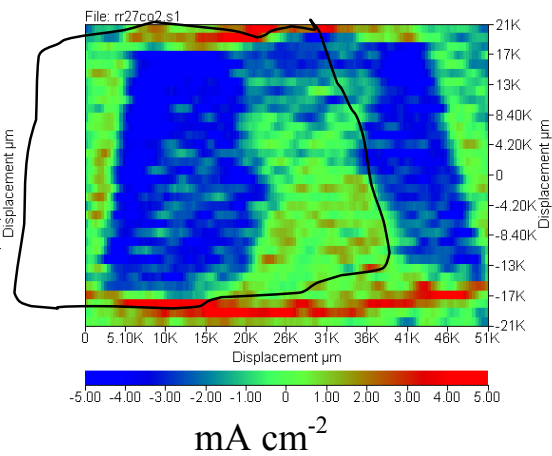

4 hours

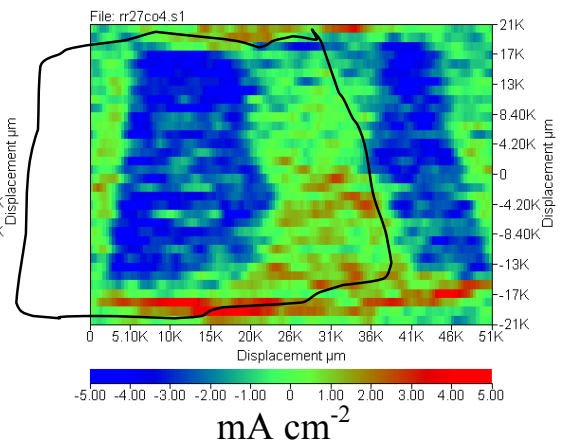

Figure 5: Showing the SVET area map scan on welded joints designated of St-1 within chloride solution saturated with $\mathrm{CO}_{2}$ for different time scans. 

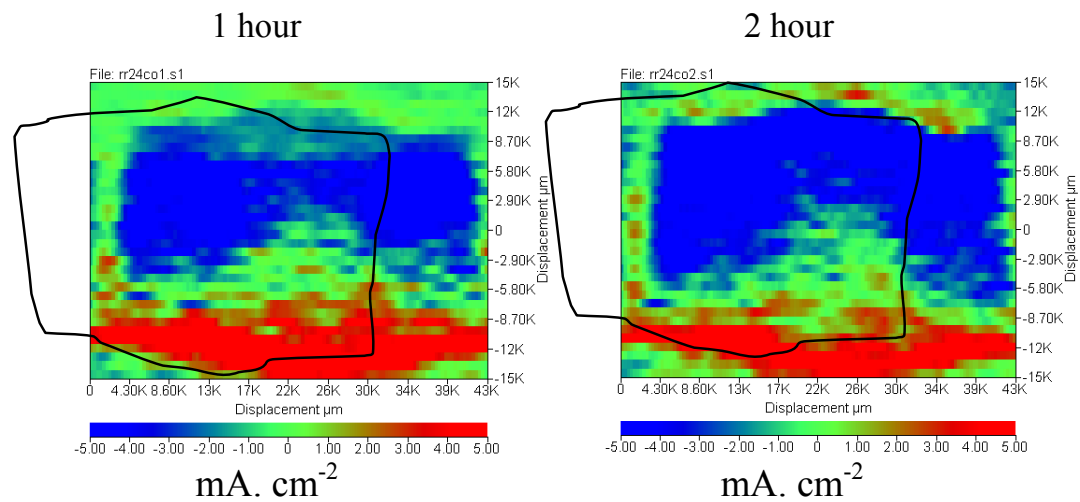

3 hours

4 hours

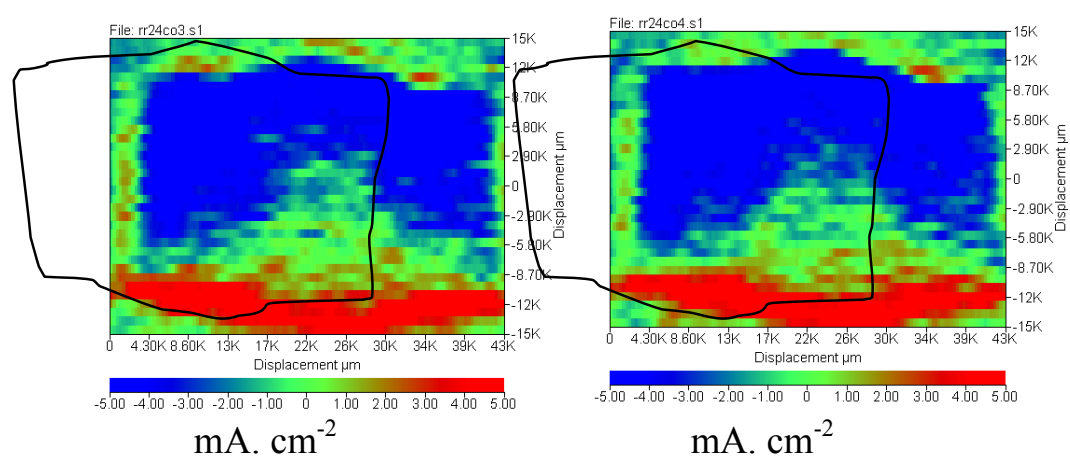

Figure 6: Showing the SVET area map scan on welded joints designated of St-2 within chloride solution saturated with $\mathrm{CO}_{2}$ for different time scans.

\section{Conclusions}

The scanning microtip electrode is vibrated relative to the scanned surface and registers an alternating potential at the vibration frequency, this potential being proportional to electrical field strength or potential gradient in the direction of the vibration. The alternating potential arises from the oscillation of the microtip in the potential field generated ohmically by the ionic current flux passing through the electrolyte. SVET resolution and output signal is dependent upon the conductivity of the solution, low conductivity solution were used for this analysis. It should be noted that resolution and output signal decrease with increasing conductivity. The scanning vibrating electrode technique was found to be a sensitive and reliable technique that can be used for rapid and reliable evaluation of weldments.

Results of the map scans over weldments show that, although the activity varied from time to time, the most pronounced attack seemed to be higher 
localised activity in the weld metal and/or the heat affected zone after duration of time and least activity showed in the parent plate, moreover to be concentrated in the bainite and martensite microstructures and least activity for some steels occurred in the pearlite and ferrite microstructure. It can be concluded that the corrosion measurements showed a clear significant differences in the corrosion behaviours between the weld zone and parent plate microstructures, i.e., some location for welded steel microstructures are more harmed or attacked than others.

\section{References}

[1] H. S. Isaacs and B. Vyas, Electrochemical Corrosion Testing, ASTM STP 727, 1981, pp. 3.

[2] H.S. Isaacs and Y. Ishikawa, Electroch. Technique, ed. R. Baboian, Houston, TX. NACE, 1986, pp. 17.

[3] H.S. Isaacs, Corrosion Science Vol. 28, 1988, pp547.

[4] M. J. Franklin et al., Corrosion. Sci., Vol. 32, No. 9, 1991, pp. 945.

[5] T. Shibata et al., Corrosion Engineering, Vol. 39, 1990, pp. 331.

[6] R. Akid and M. Garma, Electyrochimica Acta, Vol. 49, 2004, pp. 2871. 